Article

\title{
Self-Saturable Absorption and Reverse-Saturable Absorption Effects in Diamond-Like Carbon Films with Embedded Copper Nanoparticles
}

\author{
Šarūnas Meškinis ${ }^{1, * \mathbb{D}}$, Andrius Vasiliauskas ${ }^{1}$, Mindaugas Andrulevičius ${ }^{1}{ }^{\mathbb{D}}$, \\ Aušrinè Jurkevičiūtè ${ }^{1}$, Domantas Peckus ${ }^{1}$, Vitoldas Kopustinskas ${ }^{1}$, Karolis Viskontas ${ }^{2}$ and \\ Sigitas Tamulevičius ${ }^{1}$ (D) \\ 1 Institute of Materials Science, Kaunas University of Technology, K. Baršausko Str. 59, LT-51423 Kaunas, \\ Lithuania; andrius.vasiliauskas@ktu.lt (A.V.); mindaugas.andrulevicius@ktu.lt (M.A.); \\ Ausrine.Jurkeviciute@ktu.lt (A.J.); domantas.peckus@ktu.lt (D.P.); vitoldas.kopustinskas@ktu.lt (V.K.); \\ sigitas.tamulevicius@ktu.lt (S.T.) \\ 2 JSC Ekspla, Savanoriu Str. 237, LT-02300 Vilnius, Lithuania; karolis.viskontas@gmail.com \\ * Correspondence: sarunas.meskinis@ktu.lt; Tel.: +370-37-313432
}

Received: 18 December 2018; Accepted: 2 February 2019; Published: 7 February 2019

\begin{abstract}
Nonlinear optical properties (self-saturable absorption and reverse-saturable absorption) of diamond-like carbon films with variable amounts of embedded copper nanoparticle (DLC:Cu) films deposited by high power pulse magnetron sputtering were studied in dependence on deposition conditions. X-ray photoelectron spectroscopy was used to study elemental composition and $\mathrm{He}$ ion microscopy to study changes of the size, shape, and concentration of the $\mathrm{Cu}$ nanoparticles deposited using different pulse currents as well as argon and acetylene gas ratios. Raman scattering spectra of DLC:Cu films studied were typical of diamond-like carbon (including the films with a high $\mathrm{Cu}$ atomic concentration where it was up to 60 atom \% and carbon atomic concentration was less than 20 atom \%). In all cases, in the absorption spectra of DLC:Cu films, the surface plasmon resonance-related peak was recorded. The position of the plasmonic peak for all the deposited nanocomposite films was in a 590-620 nm range. For the samples containing lower amounts of copper, reverse-saturable absorption was found. Transient optical absorption measurements have shown that the reverse-saturable absorption is typical for the samples with a lower relaxation time. The longer relaxation times recorded during transient optical absorption measurements correlated with the presence of the saturable absorption effect. For DLC:Cu samples containing 58-62 atom \% $\mathrm{Cu}$, some optical inhomogeneities were observed. The samples in different places demonstrated either saturable absorption or reverse-saturable absorption. The presence of both saturable and reverse-saturable absorption effects in the same sample is explained by the lateral inhomogeneities of the DLC:Cu films.
\end{abstract}

Keywords: diamond-like carbon films with embedded copper nanoparticles; high power impulse magnetron sputtering; surface plasmon resonance; saturable absorption; reverse-saturable absorption

\section{Introduction}

Ultrafast fiber lasers (pulse time $<10 \mathrm{ps)}$ ) are compact, simple, maintenance-free coherent light sources, with a long operation lifetime, usually operating at operation wavelengths of 1000-2000 $\mathrm{nm}[1,2]$. They are widely used in femto-chemistry, spectroscopy, two-photon microscopy, optical metrology, medicine, and laser micromachining [1-3]. Mode locking in these lasers is performed by using self-saturable absorber mirrors. Semiconductor saturable absorbance mirrors (SESAMs) are most often used for mode locking $[1,2,4]$. However, an expensive and complex molecular beam epitaxy technique is 
used for the deposition of SESAMs. Moreover, SESAMs are an inflexible and bulky solution for fiber lasers with a narrow operation range $(<\sim 100 \mathrm{~nm})$ [4].

Structures based on plasmonic group IB metal $(\mathrm{Au}, \mathrm{Ag}$, or $\mathrm{Cu})$ nanoparticles are of considerable interest as an alternative to SESAMs. A large modulation depth and simple fabrication technology are advantages of such plasmonic saturable absorbers [5,6]. For example, in [7], the highest nonlinear optical absorption coefficient was observed for the excitation wavelength that was equal to the wavelength of localized surface plasmon resonance.

On the other hand, strong modulation of the optical transmittance with increased light intensity was reported for excitation wavelengths substantially higher than the plasmonic peak wavelength. Particularly, a depth as high as 16\% was reported for Au nanorods in [8], the saturable absorption and modulation being at the excitation wavelength of $1560 \mathrm{~nm}$, while wavelengths corresponding to the localized surface plasmon resonances were 532 and $1145 \mathrm{~nm}$. According to [8], the concentration and the aspect ratios distribution of Au nanorods had a significant influence on the nonlinear optical properties of the studied samples. While the dimension and spatial distribution of the gold nanorods had significantly less influence [8].

In [9], it was shown that optical transmittance of the $\mathrm{Ag} /$ silica gel glass nanocomposites increased by more than $10 \%$ at a $1064 \mathrm{~nm}$ excitation wavelength, while their plasmonic peak wavelength was in the $400-550 \mathrm{~nm}$ range. A similar situation was reported in [10], where a gold nanocrystal and sodium carboxymethylcellulose nanocomposite optical transmittance was found to be increased more than $10 \%$ at a $1560 \mathrm{~nm}$ excitation wavelength, while their plasmonic peak wavelength was approximately $600 \mathrm{~nm}$.

In summary, $\mathrm{Au}$ and $\mathrm{Ag}$ nanoparticles (or nanorods) are most often studied as plasmonic saturable absorbers. However, Au is relatively expensive. An Ag surface plasmon resonance peak is blue-shifted in comparison with $\mathrm{Au}$ and $\mathrm{Cu}[11,12]$. Thus, $\mathrm{Ag}$ plasmonic resonance wavelength usually is more distant from the fiber lasers operation wavelengths range. On the other hand, in some cases, saturable absorption (i.e., the increase in optical transmittance with increased light intensity) was observed for $\mathrm{Cu}$ nanoparticles. In [13], enhanced nonlinear optical responses were observed in the copper nanocluster-glass composites synthesized by $\mathrm{Cu}$ implantation in glass followed by thermal treatments. Recently, $\mathrm{Cu}$ nanowire-based saturable absorbers operating in a visible light range was demonstrated [14]. The operation of Q-switched fiber laser in a near infrared range employing thin films with $\mathrm{Cu}$ nanoparticles was demonstrated in [15]. However, no specific data on $\mathrm{Cu}$ nanoparticles used or their linear optical properties were presented in that study.

It should be mentioned that, in numerous studies, the transition from the saturable effect to the reverse-saturable effect was observed with increased light intensity [7,9,16-20]. However, usually, high optical power density was necessary to achieve such a change. It was $\sim 8.5 \mathrm{GW} / \mathrm{cm}^{2}$ in [7], between the 2.6 and $6.6 \mathrm{GW} / \mathrm{cm}^{2}$ in [9], $>1.6 \mathrm{GW} / \mathrm{cm}^{2}$ in [17], $1.5 \mathrm{GW} / \mathrm{cm}^{2}$ in [18], and $0.2 \mathrm{GW} / \mathrm{cm}^{2}$ in [16]. In [19], optical transmittance of the $\mathrm{Cu}$ nanoclusters began to decrease at power densities $>1 \mathrm{GW} / \mathrm{cm}^{2}$. Similar results were reported for $\mathrm{Ag}$ nanoparticles [20]. The reverse-saturable absorption in plasmonic materials at excitation powers $<0.125 \mathrm{GW} / \mathrm{cm}^{2}$ had rarely been observed before recently. Particularly, in [16], the smallest gold atomic clusters $(<2 \mathrm{~nm})$ exhibited reverse-saturable absorption at the wavelength corresponding to the surface plasmon wavelength of larger gold nanocrystals. However, for these samples, no surface plasmon resonance effect was reported. Recently, reverse-saturable absorption at low exciting optical power density was reported for Ag nanoprisms [21]. However, in that study, continuous wave laser was used. The observed effect was explained by a two-photon absorption model.

Linear and nonlinear optical characteristics of the plasmonic nanocomposites may have advantages over the nanoparticles in terms of the increased absorbance $[9,10]$. Recently, it was shown that plasmonic nanoparticles can cause a stronger nonlinear absorption when embedded in other materials due to the combination of the surface plasmon resonance and Purcell effect [22]. 
Diamond-like carbon (DLC) is a metastable form of amorphous carbon consisting of carbon bonded by sp ${ }^{2}$ (graphite-like) and $\mathrm{sp}^{3}$ (diamond-like) bonds [23]. Besides that, DLC can contain up to several tens of atomic percent of hydrogen [23]. DLC films are hard, wear- and corrosion-resistant, and biocompatible [23]. Optical properties of these films can be tuned in a wide range. Usually DLC films are deposited at room temperature by plasma-assisted methods [23]. Properties of the DLC films can be additionally controlled by doping. In the case of the DLC nanocomposites containing Au, $\mathrm{Ag}$, or $\mathrm{Cu}$, segregation of the metal and growth of the group IB metal nanoparticles inserted into the amorphous carbon matrix takes place due to the fact that $\mathrm{Au}, \mathrm{Ag}$, and $\mathrm{Cu}$ are relatively inert with carbon $[12,24]$. The surface plasmon resonance effect was reported for DLC films with embedded Au, $\mathrm{Ag}$, or $\mathrm{Cu}$ nanoparticles (please see [12] and references therein).

Taking into account the properties mentioned above, the DLC nanocomposite films with embedded plasmonic $\mathrm{Au}, \mathrm{Ag}$, or $\mathrm{Cu}$ nanoparticles seem to be a prospective material for fabrication of the saturable absorbers. Having in mind the role of diamond-like carbon or graphite-like carbon particles in the absorbance self-saturation effect described in [25], one can expect tunable properties of DLC with embedded metallic nanoparticles. However, despite very intensive and numerous investigations on DLC films and DLC nanocomposites containing $\mathrm{Au}, \mathrm{Ag}$, or $\mathrm{Cu}$, nonlinear optical properties including the saturable absorption effect of this material have not been systematically studied.

This research is aimed at studies of nonlinear optical properties of the hydrogenated DLC nanocomposite films with embedded $\mathrm{Cu}$ nanoparticles as a potential saturable absorber.

\section{Materials and Methods}

DLC:Cu films were deposited by unbalanced reactive high power pulse magnetron sputtering (HIPIMS). Samples for the structural and composition studies were synthesized on monocrystalline $\mathrm{Si}(100)$ as a most convenient substrate for DLC deposition. Samples for the studies of linear and nonlinear optical properties as well ultrafast optical phenomena were deposited on fused silica substrates. The diameter of the magnetron copper target was 3". Argon was used as a sputtering gas and acetylene $\left(\mathrm{C}_{2} \mathrm{H}_{2}\right)$ was used as a source of carbon and hydrogen. Base pressure in the deposition chamber was $5 \times 10^{-4} \mathrm{~Pa}$ and work pressure $(4 \pm 1) \times 10^{-1} \mathrm{~Pa}$ was maintained throughout the deposition process. In all experiments, the substrate-target gap was set at $0.1 \mathrm{~m}$, and the substrates were grounded. The thickness of the deposited films in all cases was in the range of 50-100 nm. More details on the deposition conditions are presented in Table 1. For comparison purposes, undoped hydrogenated DLC film was deposited by ion beam deposition using an anode layer ion source. Furthermore, $800 \mathrm{eV}$ ion beam energy was used. More information on the deposition conditions and structure of such films can be found in [26].

Table 1. Deposition conditions used in the present research.

\begin{tabular}{ccccccccc}
\hline Sample No. & $\begin{array}{c}\text { Ar Gas Flow } \\
(\mathbf{s c c m})\end{array}$ & $\begin{array}{c}\mathbf{C}_{\mathbf{2}} \mathbf{H}_{\mathbf{2}} \text { Gas Flow } \\
(\mathbf{s c c m})\end{array}$ & $\begin{array}{c}\mathbf{C}_{\mathbf{2}} \mathbf{H}_{\mathbf{2}} / \mathbf{A r} \\
\text { Flux Ratio }\end{array}$ & $\begin{array}{c}\text { Pulse } \\
\text { Current (A) }\end{array}$ & $\begin{array}{c}\text { Pulse on Time } \\
\left(\boldsymbol{t}_{\text {on }}\right)(\boldsymbol{\mu s})\end{array}$ & $\begin{array}{c}\text { Pulse } \\
\text { Period }(\boldsymbol{\mu s})\end{array}$ & $\begin{array}{c}\text { Duty Cycle } \\
(\%)\end{array}$ & $\begin{array}{c}\text { Frequency } \\
(\mathbf{H z})\end{array}$ \\
\hline I30C30 & 63 & 30 & 0.48 & 30 & 100 & 10000 & 1 \\
I30C15 & 63 & 15 & 0.24 & 30 & 100 & 1000 & 1 \\
I30C12 & 63 & 12 & 0.19 & 30 & 100 & 1000 & 1 \\
I30C10 & 63 & 10 & 0.16 & 30 & 100 & 10000 & 1 \\
I30C5 & 63 & 5 & 0.08 & 30 & 100 & 10000 & 1 \\
I30C2 & 63 & 2 & 0.03 & 30 & 100 & 10000 & 1 \\
I3C7.8 & 56 & 7.8 & 0.14 & 3 & 100 & 10000 & 1 \\
I3C3.9 & 56 & 3.9 & 0.07 & 3 & 100 & 10000 & 1 \\
\hline
\end{tabular}

Raman scattering measurements were performed using a Raman microscope inVia (Renishaw, UK) with $532 \mathrm{~nm}$ wavelength excitation. The integration time was $100 \mathrm{~s}$, a power was $1.5 \mathrm{~mW}$, and the grating groove density was 2400 grooves $/ \mathrm{mm}$. Parameters of the Raman scattering spectra related to $\mathrm{sp}^{3} / \mathrm{sp}^{2}$ bond ratio such as position of $\mathrm{G}$ peak, full width at half maximum of $\mathrm{G}$ peak (FWHM), and $D / G$ peak area ratio were determined by fitting the experimental curves by Gaussian form components using XPS peak v3.1 software. It should be mentioned that the D to G peak intensity 
(area) ratio usually decreases with the increase of the $\mathrm{sp}^{3} / \mathrm{sp}^{2}$ ratio. The position of the $\mathrm{G}$ peak usually downshifts with the decrease of the $\mathrm{sp}^{3} / \mathrm{sp}^{2}$ ratio, and saturation at higher ratios $(>0.6)$ takes place $[23,27]$. Full width at half maximum of the $G$ peak usually increases with $\mathrm{sp}^{3}$ content for low $\mathrm{sp}^{3}$-hydrogenated DLC and decreases with $\mathrm{sp}^{3}$ content for high $\mathrm{sp}^{3}$-hydrogenated DLC [28].

A Thermo Scientific ESCALAB 250Xi spectrometer (Thermo Fisher Scientific, East Grinstead, $\mathrm{UK})$ with a monochromatic $\mathrm{Al} \mathrm{K \alpha}$ radiation $(h v=1486.6 \mathrm{eV})$ was used for X-ray photoelectron spectroscopy (XPS) measurements. The base pressure in the analytical chamber was lower than $2 \times 10^{-7} \mathrm{~Pa}$. The 40 and $20 \mathrm{eV}$ pass energy values of a hemispherical electron energy analyzer were used for the survey and for the recording of high-resolution spectra, respectively. The energy scale of the system was calibrated with respect to $\mathrm{Au} 4 f_{7 / 2}, \mathrm{Ag} 3 d_{5 / 2}$, and $\mathrm{Cu} 2 p_{3 / 2}$ peak positions. The samples were measured as-prepared and after cleaning with Ar ions at the energy $500 \mathrm{eV}$ for $50 \mathrm{~s}$. The Thermo Scientific Advantage software (v5.979) was used for the peak fitting procedure using a sum of Lorentzian-Gaussian (30:70) functions for all elements, and Lorentzian-Gaussian (80:20) functions for metallic $\mathrm{Cu}$ and graphitic carbon $\left(\mathrm{sp}^{2}\right)$.

Morphology of the DLC:Cu nanocomposite films on silicon substrates was investigated employing a helium ion microscope (ORION NanoFab, Zeiss, Oberkochen, Germany), which enables high spatial resolution imaging using a focused ion beam. Scan dwell time was $2 \mu \mathrm{m}$, beam current was in 0.223-0.322 pA range.

Transmission and reflection spectra of the DLC:Cu nanocomposites on fused silica substrates were obtained using a stabilized halogen light source (SLS301, ThorLabs, Newton, MA, USA), integrating a sphere (RTC-060-SF, Labsphere, North Sutton, NH, USA) and high-sensitivity spectrometer (Maya 2000Pro, Ocean Optics, Largo, FL, USA). The spectra were recorded in a wavelength range of 360-1100 nm (limited by a light source and spectrometer). For the transmission measurements, samples were mounted in the front port of the integrating sphere, while for the reflection measurements they were mounted in the back port at the incidence angle of $8^{\circ}$. Before each measurement, dark and reference spectra from a quartz substrate were recorded. The absorption $(A)$ was calculated as $A=1-T-R$, where $T$ is the transmission, and $R$ is the reflection in arbitrary units.

Ultrafast optical processes were investigated employing a transient absorption spectrometer HARPIA (Light Conversion, Vilnius, Lithuania). The samples were excited using ultrafast Yb:KGW laser Pharos (Light Conversion, Vilnius, Lithuania) with a regenerative amplifier generating a $66.7 \mathrm{kHz}$ repetition rate and $290 \mathrm{fs}$ duration pulses at a $1030 \mathrm{~nm}$ wavelength. The proper excitation wavelength chosen from the highest absorption amplitude in the steady state absorption spectra in most cases was tuned to $660 \mathrm{~nm}$ with a collinear optical parametric generator Orpheus and harmonic generator Lyra (Light Conversion, Vilnius, Lithuania). The excitation intensity for the DLC sample containing 59.59, $62.04,63.46,73.8$, and 81.2 atom $\%$ of $\mathrm{Cu}$ were excited with $50 \mu \mathrm{J} / \mathrm{cm}^{2}$ intensity at $660 \mathrm{~nm}$. The samples were probed with a white light supercontinuum generated using a $2 \mathrm{~mm}$ thick sapphire plate excited with a fundamental laser wavelength at $1030 \mathrm{~nm}$. The spectral range of supercontinuum as well as the detection range of the transient absorption spectra dynamics were from 507 to $810 \mathrm{~nm}$. The excitation beam was focused to a spot of about $700 \mu \mathrm{m}$ in diameter, while the probe white light supercontinuum beam diameter was of about $500 \mu \mathrm{m}$.

Nonlinear optical response of the samples was investigated by a nonlinear reflectance measurement system with a picosecond mode locked fiber laser, which can be used as a tunable light source (1020-1080 $\mathrm{nm}$ range) (JSC Ekspla, Vilnius, Lithuania). The advantage of this measurement method over the widely used Z-scan technique is its relative simplicity. This measurement setup is all-fiber. Therefore, the measurement system cannot be misadjusted. There are no movable parts in this case, and the system can be fully automated. The samples were placed on a dielectric Bragg mirror. A laser beam of $1064 \mathrm{~nm}$ wavelength and a $6.6 \mu \mathrm{m}$ diameter was used for excitation. Pulse time was approximately $8 \mathrm{ps}$. The maximum excitation fluence used was $1 \mathrm{~mJ} / \mathrm{cm}^{2}$ (maximum optical power $0.125 \mathrm{GW} / \mathrm{cm}^{2}$ ). The nonlinear optical response was measured at $1064 \mathrm{~nm}$, too. More information on the experimental setup used can be found in [29]. 


\section{Results}

\subsection{Composition}

High-resolution XPS spectra of oxygen, carbon, and copper for the DLC:Cu films were acquired before and after extra $\mathrm{Ar}^{+}$surface sputtering, for the surface composition analysis and possible chemical bonds detection. Atomic elemental concentration of the surface of the samples are presented in Table 2. Data presented in this table shows a significant increase in copper content on the surface after the applied sputtering procedure.

Figure 1 illustrates the dependence of the chemical composition of the DLC:Cu films on deposition conditions. Analysis of the ion beam etched DLC:Cu films revealed an increase in the $\mathrm{Cu}$ atomic concentration with the pulse current used. $\mathrm{Cu}$ atomic concentration increased with $\mathrm{C}_{2} \mathrm{H}_{2} / \mathrm{Ar}$ gas flow ratio at lower pulse ratios. At the higher acetylene and argon gas flow ratios, the copper amount in the DLC:Cu films saturated and was in the 55-65 atom \% range. No clear dependence of the oxygen atomic concentration on the deposition conditions was found. The oxygen amount was 13-20 atom \%.

Table 2. Atomic concentration of the studied DLC:Cu samples.

\begin{tabular}{ccccccc}
\hline \multirow{2}{*}{ Sample No. } & \multicolumn{3}{c}{ Untreated Samples } & \multicolumn{3}{c}{ Sputtered Samples } \\
\cline { 2 - 7 } & Cu 2 $p$ & O 1s & C 1s & Cu 2 $p$ & O 1s & C 1s \\
\hline I30C10 & 14.14 & 30.32 & 55.54 & 62.04 & 19.77 & 18.19 \\
I30C5 & 23.66 & 29.41 & 46.94 & 59.59 & 18.47 & 21.93 \\
I30C2 & 28.71 & 29.21 & 42.08 & 63.46 & 20.93 & 15.61 \\
I30C30 & 10.89 & 33.02 & 56.09 & 26.23 & 15.85 & 57.92 \\
I3C7.8 & 5.15 & 20.59 & 74.26 & 21.74 & 18.68 & 59.57 \\
I3C3.9 & 13.55 & 28.54 & 57.9 & 55.39 & 13.3 & 31.31 \\
\hline
\end{tabular}

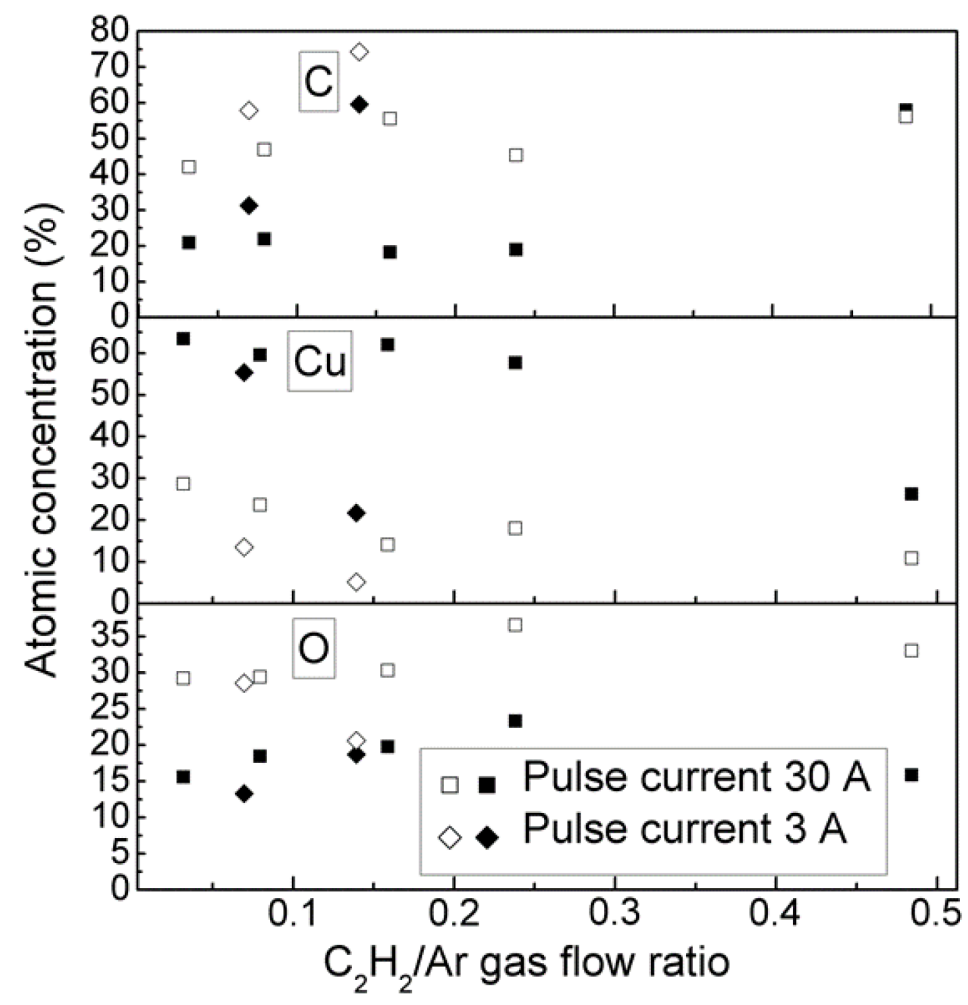

Figure 1. Dependence of the composition of the DLC:Cu films on $\mathrm{C}_{2} \mathrm{H}_{2}$ / Ar gas flow ratio. Hollow symbols refer to the air exposed samples and solid symbols refer to the samples after the in situ ion beam cleaning in the XPS chamber. 


\subsection{Morphology and Structure}

According to Figure 2, one can see that number of the $\mathrm{Cu}$ nanoclusters increased with the increase in copper atomic concentration, while changes of the nanoparticle size were minor. Afterwards, coalescence of the $\mathrm{Cu}$ nanoparticles and formation of the $\mathrm{Cu}$ network followed. However, for some DLC:Cu samples containing approximately 60 atom \% of copper, spherical $\mathrm{Cu}$ nanoparticles were seen. While in other samples containing nearly the same amount of copper, substantially larger coalesced $\mathrm{Cu}$ nanoparticles were observed. The sample I3C 3.9, containing 55.39 atom \% Cu, falls out of this order. For this sample, non-homogeneously distributed spherical nanoparticles of different size can be seen on the sample's surface. It should be mentioned that we observed similar effects in a previous study where the dependence of the $\mathrm{Cu}$ nanocluster size and the shape on the HIPIMS pulse current was demonstrated [30].

Two typical He ion microscope images of the sample I30C10 measured at different places of the investigated film surface were additionally analyzed. The results are presented in Figure 3. One can see that, for these two arbitrary selected points, there are differences in nanoparticle size and shape statistics. In one case (Point No. 1) there were larger and more prolonged nanoparticles, while in the other case (Point No. 2) there were smaller and spherical nanoparticles.

Typical Raman scattering spectra of the DLC:Cu films are presented in Figure 4a. In all cases Raman scattering spectra of the studied films were typical for diamond-like carbon $[23,27]$. Broad Raman scattering spectral feature consisting of the main peak and shoulder can be seen in the 1200-1700 $\mathrm{cm}^{-1}$ wavenumber range. The main peak at $\sim 1500-1600 \mathrm{~cm}^{-1}$ can be described as the $\mathrm{G}$ peak, related to the stretching vibration mode of $\mathrm{sp}^{2}$-bonded carbon. The shoulder at $\sim 1200-1400 \mathrm{~cm}^{-1}$ can be defined as a disorder-induced $\mathrm{D}$ peak related to the breathing mode vibrations of $\mathrm{sp}^{2}$-bonded carbon rings [23,27]. The shape of the spectra in all cases was rather similar, despite the fact that copper content in the films changed within a broad range (20-60 atom \%). The Raman scattering spectra of the samples were typical for DLC, even in the case when carbon content in the films dropped to 20 atom \%. It should be mentioned that such a result is not unique. In [31], Raman scattering spectra typical for DLC were observed for amorphous carbon films containing 50 atom $\% \mathrm{Cu}$, while in [32] the shape of the Raman scattering spectra of the hydrogenated DLC:Cu films was similar to that of the spectra typical for DLC and nearly the same for samples containing 27.85 atom $\%$ and 77.31 atom \% of copper.

The dependence of the $\mathrm{D} / \mathrm{G}$ peak area ratio on acetylene and argon gas flow ratio is presented in Figure $4 \mathrm{~b}$. Non-monotonous dependence can be seen, and the D/G ratio was 1-2.
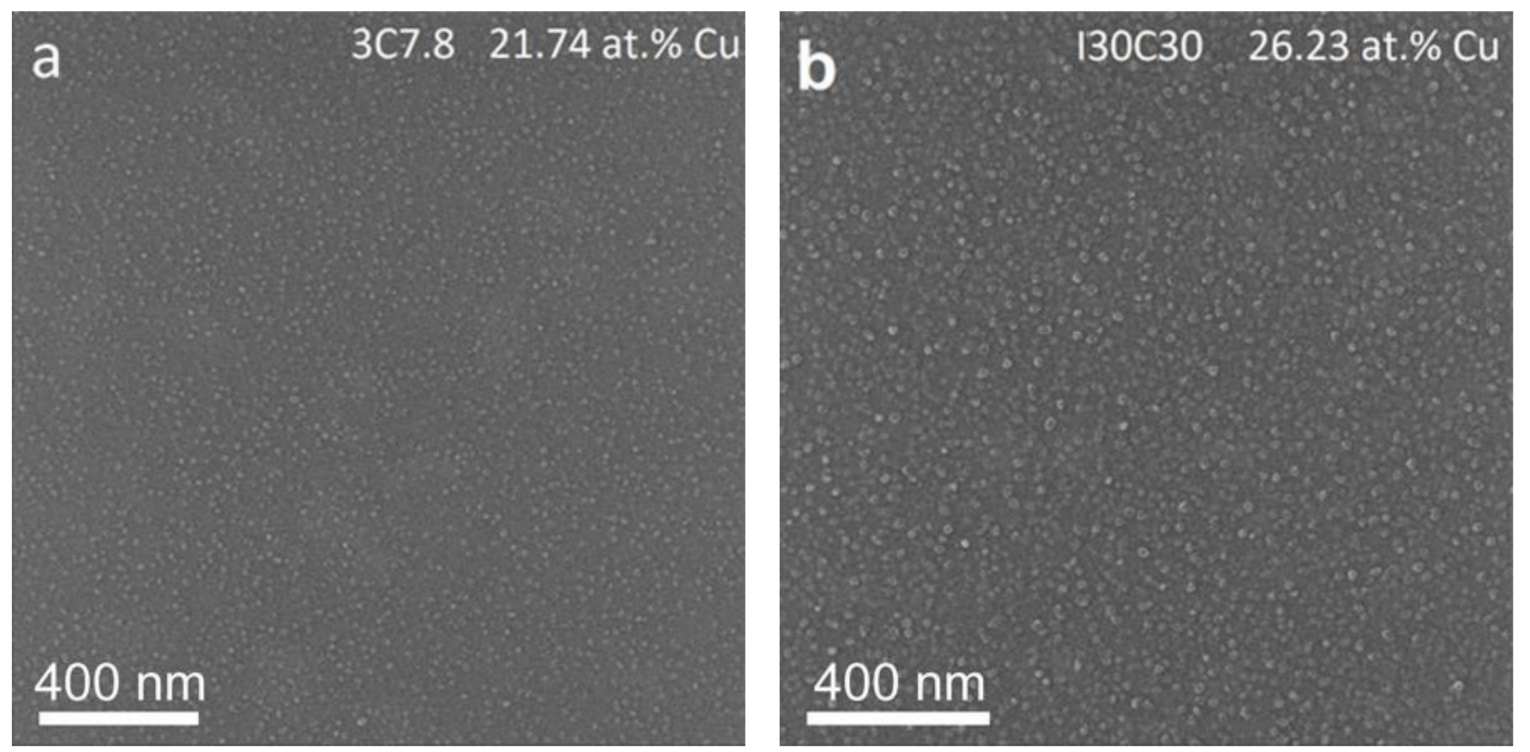

Figure 2. Cont. 


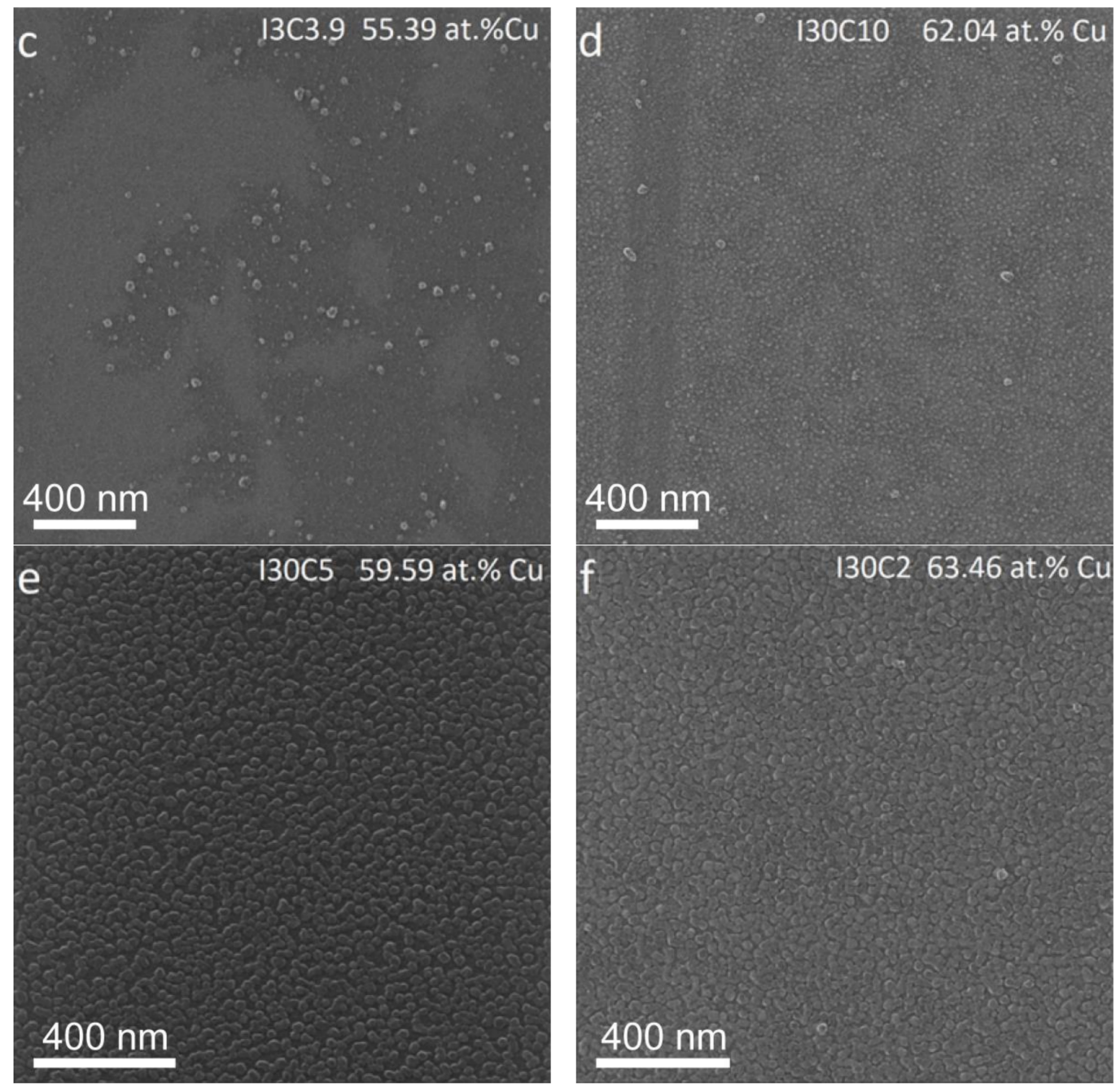

Figure 2. Typical He ion beam microscope photos of the DLC:Cu films: Sample No. I3C7.8 (a), Sample No. I30C30 (b), Sample No. I3C3.9 (c), Sample No. I30C10 (d), Sample No. I30C5 (e), and Sample No. I30C2 (f).
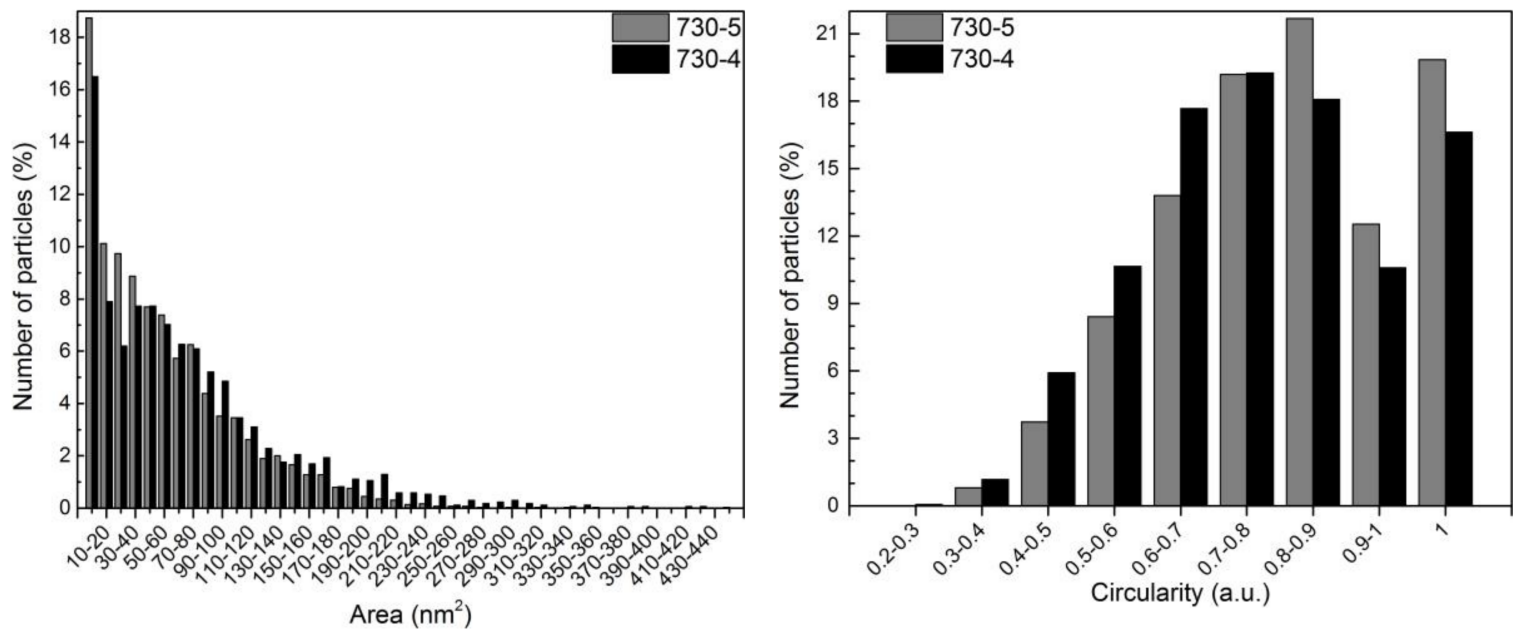

Figure 3. The number of particles vs. the Cu nanoparticle area (a), and the number of particles vs. the circularity of the $\mathrm{Cu}$ nanoparticles $(\mathbf{b})$. 

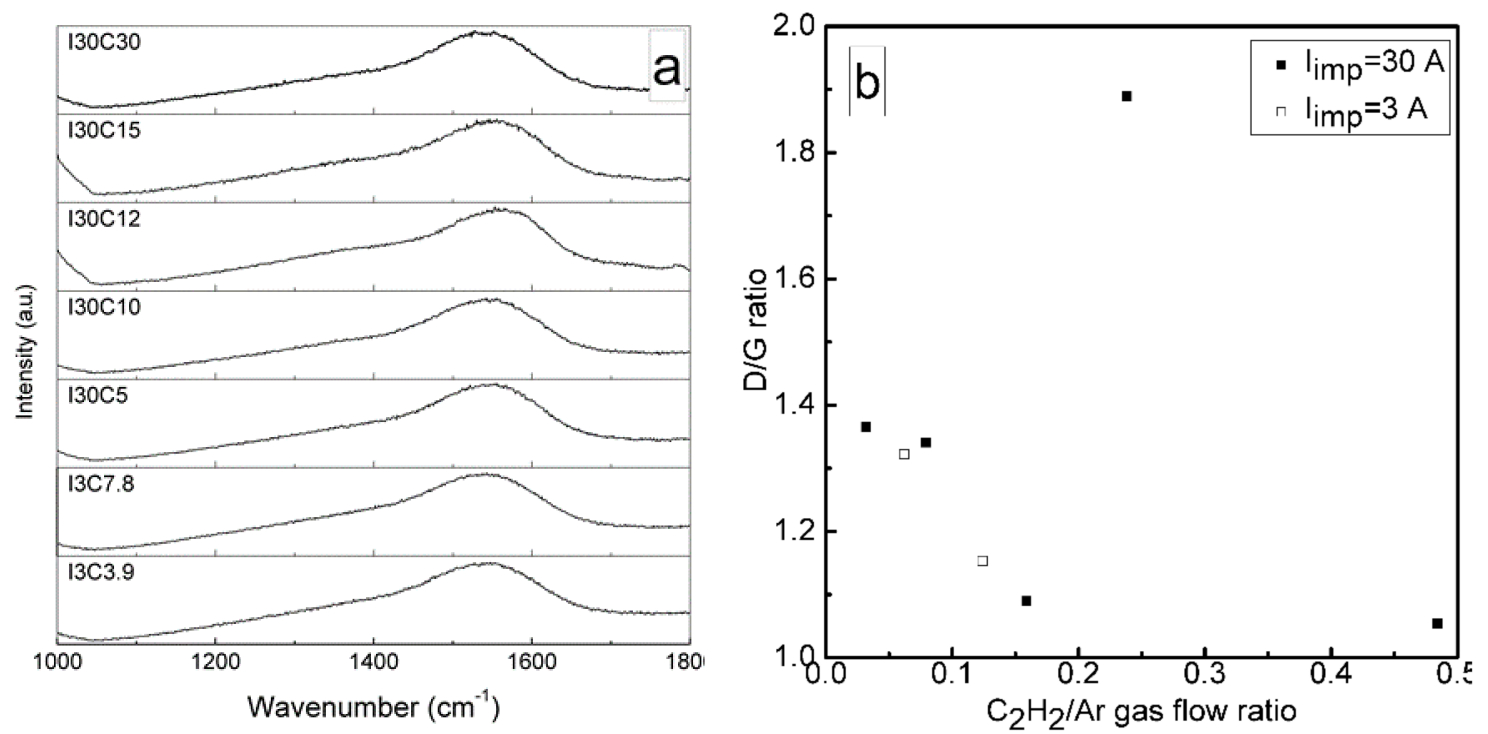

Figure 4. Typical Raman scattering spectra of DLC:Cu films (a), and the D/G ratio vs. acetylene/argon gas flow ratio $(\mathbf{b})$.

\subsection{Linear Optical Properties}

Typical optical reflection and absorption spectra of the DLC:Cu films are presented in Figure 5. It can be seen that, in the 750-1050 $\mathrm{nm}$ wavelength range, only a minor dependence of the reflectance of the samples on the wavelength can be found. The reflectance decreased for the films deposited with the decreased acetylene gas flow used for the deposition.

In the absorption spectra of the DLC:Cu films, the surface plasmon resonance-related peak can be seen. Despite variations of the structure of the DLC matrix (Figure 4), the huge changes in the copper amount (from 21.74 to 63.46 atom \%) (Figure 5), and the shape and size of the Cu nanoclusters (Figure 2), the appearance of the absorption spectra in all cases was rather similar. The position of the plasmonic peak maximum was rather similar, too (in the 590-620 nm range).
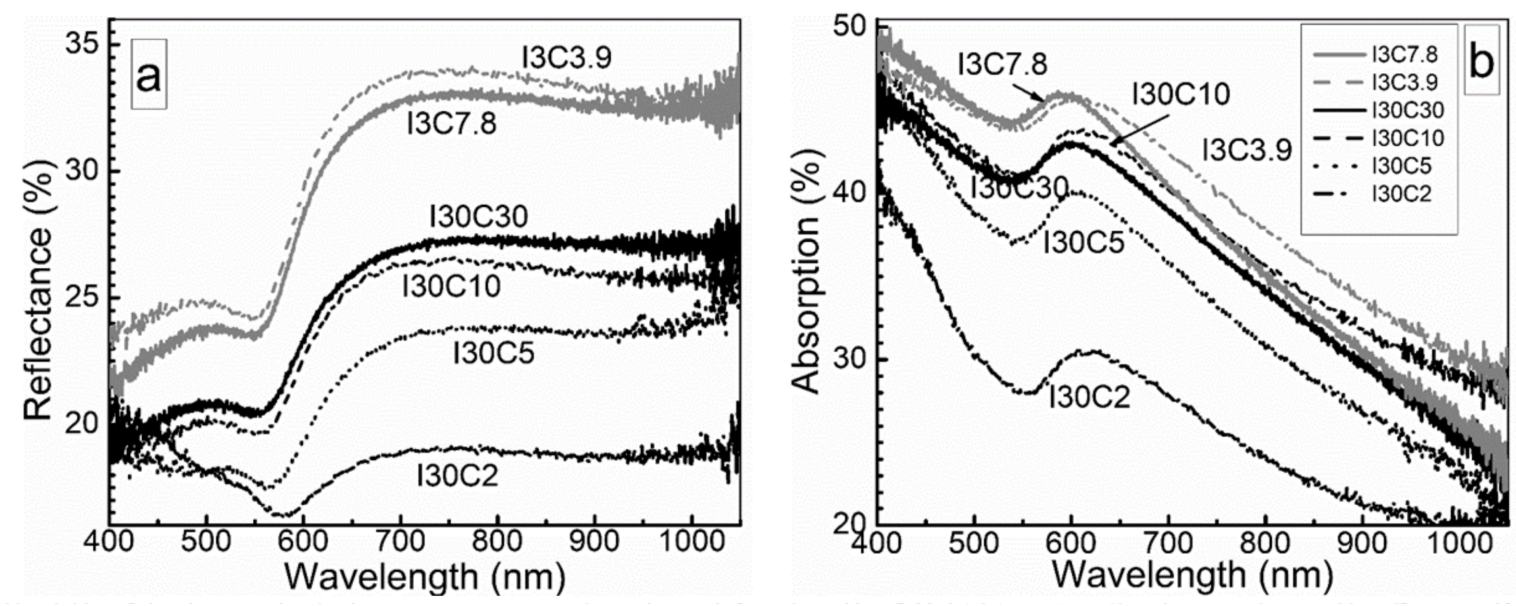

Figure 5. Reflectance (a) and absorption (b) spectra of DLC:Cu films.

\subsection{Nonlinear Optical Properties: Saturable Absorption and Reverse-Saturable Absorption}

The typical reflectance dependencies versus the laser fluence presented in Figure 6 illustrate the nonlinear optical properties of the DLC:Cu samples. One can see that for the samples containing lower amounts of copper (22 and 25 atom \%) reverse-saturable absorption takes place; i.e., reflectance decreases at certain laser fluences. For the higher $\mathrm{Cu}$ content, this effect was ambiguous. For the 
samples containing 58-62 atom \% Cu, the saturable absorption effect was observed (Figure $6 \mathrm{~d}-\mathrm{f}$ ); however, in these samples, there were some spots where reverse-saturable absorption was still detected (see, e.g., Figure 6d). It should be mentioned that such a behavior of reflectance was observed despite the fact that the shape of the linear optical absorption spectra as well as the position of the plasmonic peak in all cases was rather close and relatively far from the excitation wavelength $(1064 \mathrm{~nm})$.

In addition, the dependence of the reflectance on fluence was measured for undoped hydrogenated DLC to evaluate the possible influence of amorphous diamond-like carbon matrix of the DLC:Cu films. Relatively weak reverse-saturable absorption was observed (Figure $6 \mathrm{~g}$ ).

Thus, it seems that there is no clear correlation between the linear optical absorption spectra (Figure 5) and the nonlinear optical properties of the DLC:Cu nanocomposite films (Figure 6). It should be noted that the saturable absorption was observed both in the samples containing separate $\mathrm{Cu}$ nanoparticles and in samples with agglomerations of nanoparticles as well as networks of the interconnected nanoparticles (Figures 2 and 6).

In the next step, transient absorption spectroscopy was used to study the kinetics of the excited charge carriers. The photo-excited charge carrier relaxation times were evaluated (Figure 7) for the DLC:Cu samples. We found some correlation between the relaxation time and the effect of the reverse-saturable absorption. In the case of samples with a lower charge carrier relaxation time, the reverse-saturable absorption was observed, while longer relaxation times of photo-excited carriers were typical for the samples with the saturable absorption effect.
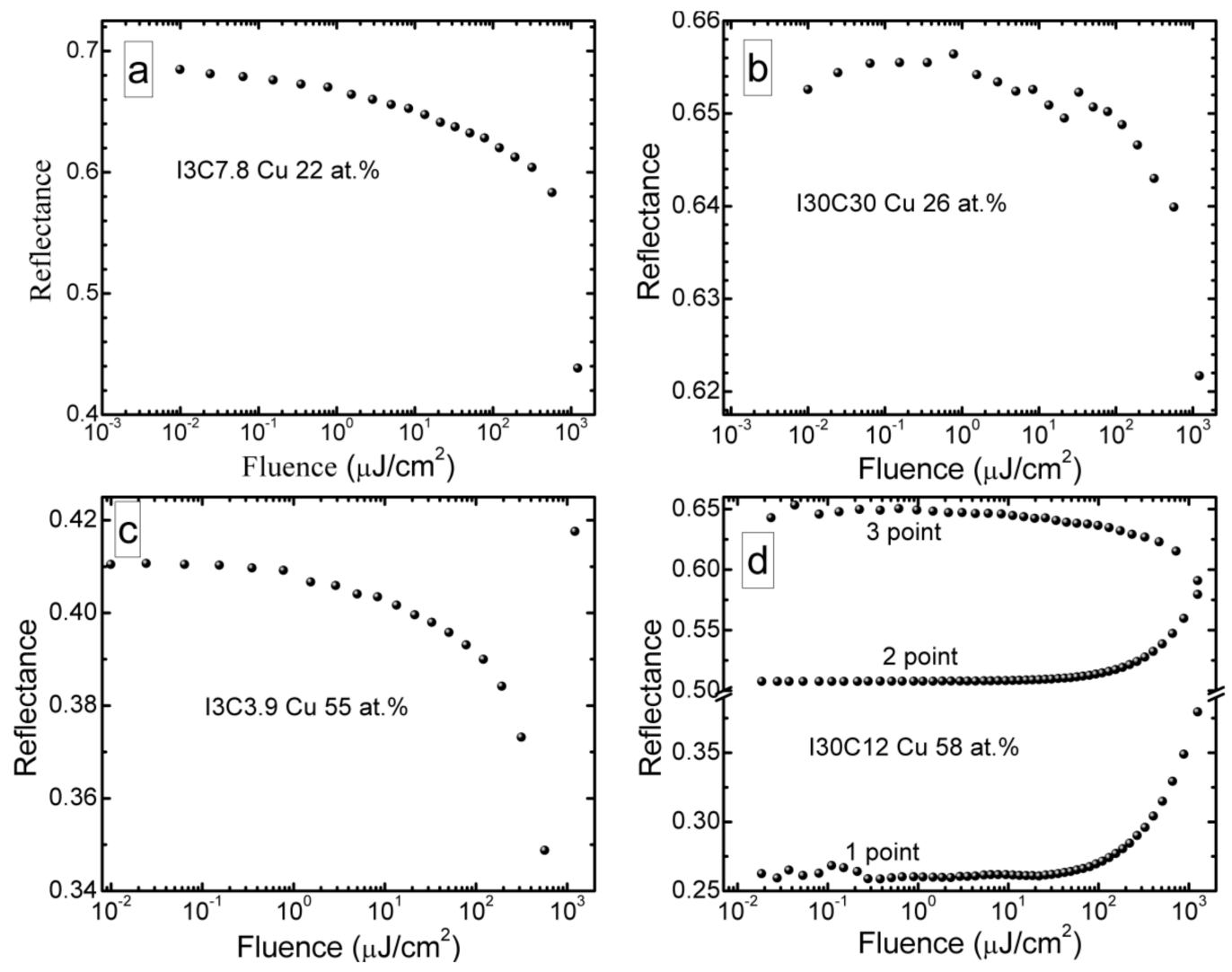

Figure 6. Cont. 

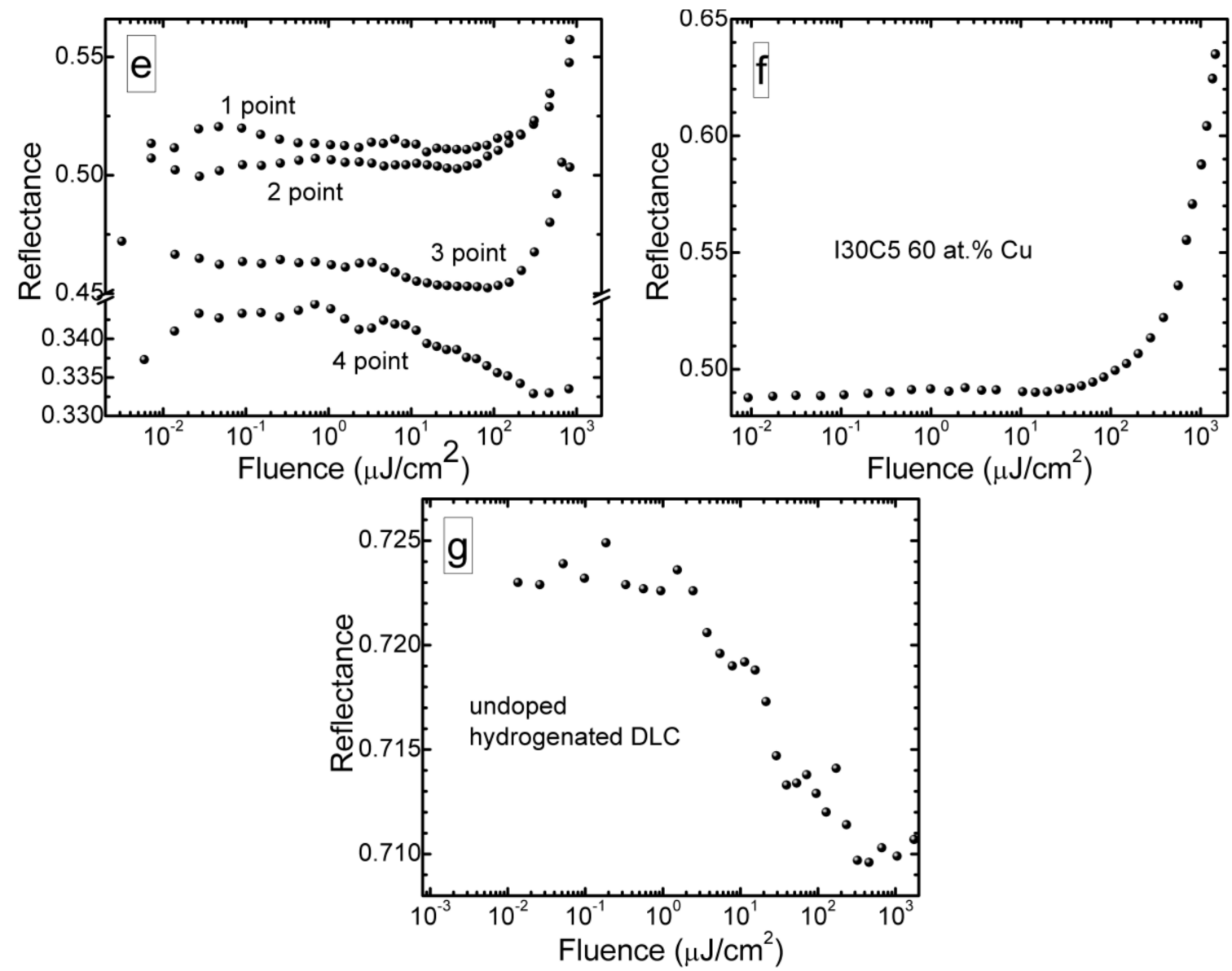

Figure 6. Reflectance vs. laser fluence for the samples I30C30 (a), I3C7.8 (b), I3C3.9 (c), I30C12 (d), I30C10 (e), and I30C5 (f) and for the undoped hydrogenated DLC (g) (typical characteristics).

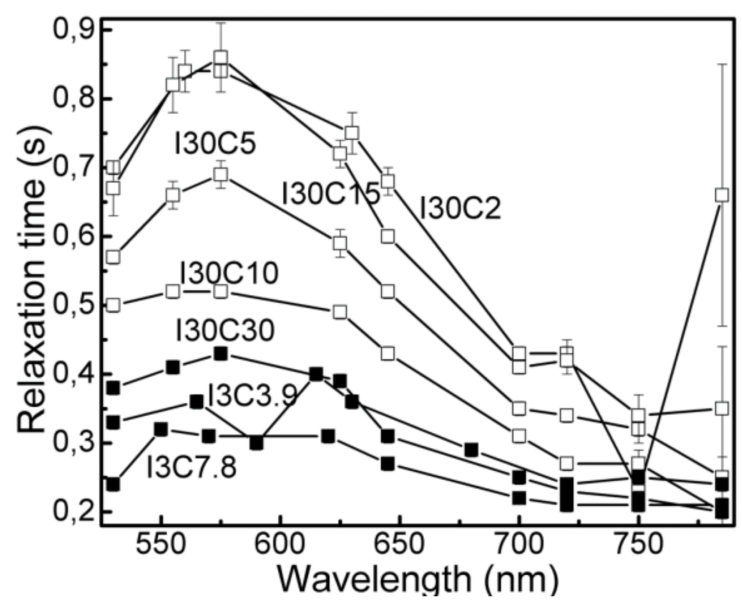

Figure 7. Relaxation time vs. wavelength of the DLC:Cu samples.

The ambiguity implied by samples where both saturable absorption and reverse-saturable absorption was observed can be explained in the following way. In our previous study, it was shown that the photoexcited charge carrier relaxation time for the DLC:Cu sample depends on the geometry of the $\mathrm{Cu}$ nanoparticles [33]. In [8], it was shown that the concentration and the aspect ratios distribution of $\mathrm{Au}$ nanorods were the main factors influencing nonlinear saturable absorption. Thus, taking into account the inhomogeneous distribution of the nanoparticle size and shape statistics in different areas of the same sample observed in this study (Figure 3), the presence of the different relaxation time areas 
in the samples can be supposed. The diameter of the laser beam used for the measurement of the nonlinear optical properties of the samples was substantially smaller than the diameter of the exciting beam used for pump-probe spectroscopy ( 6.6 and $500 \mu \mathrm{m}$, respectively). Therefore, by using pump probe spectroscopy, some averaged relaxation time was measured. Unfortunately, it is impossible to reveal smaller areas of different relaxation times.

\section{Discussion}

It should be mentioned that behavior found for the DLC:Cu nanocomposite films, similar to our case (the correlation between the saturable absorbance and relaxation time of photo-excited carriers), was reported for Au nanostructures (nanorods, nanostars, and nanoshells) in [34]. Particularly, a very similar surface plasmon resonance peak position was found for different nanostructures in optical extinction spectra. However, gold nanorods had a longer relaxation time (5.4 ps) compared to that of nanostars (3.0 ps) and nanoshells (1.8 ps). A long relaxation time in Au nanorods was consistent with strong saturable absorption. For nanoshells, weak reverse-saturable absorption was observed; however, this was explained just by the weak absorption in Au nanoshells at the laser excitation wavelength. No deeper consideration of the possible physical mechanisms was done.

Thus, the correlation between the saturable absorption sign (e.g., reverse or direct) and the relaxation time observed in the present study may be explained in the following way. It is known that the $\mathrm{Cu}$ interband transition energy is $\sim 2.1 \mathrm{eV}$ [35]. Excitation wavelength used in the present study was $1064 \mathrm{~nm}$, which corresponds to $1.17 \mathrm{eV}$. Thus, in our case, the interband transition related to absorption of one photon is impossible. This means that the saturable absorption in DLC:Cu nanocomposites is related to the intraband transitions in copper nanoparticles. Faster relaxation (recorded shorter relaxation time) makes the further excitation of the relaxed electrons and the further transfer of energy via electron-electron possible [18,36]. Such mechanisms may be two-photon absorption and/or free charge carrier absorption. Excitation energy used in the present study is high enough for two-photon absorption. In [19], reverse-saturable absorbance of the copper nanoclusters at $1064 \mathrm{~nm}$ excitation wavelength was explained by two-photon absorption; however, it was shown that transmittance began to decrease at power densities $>1 \mathrm{GW} / \mathrm{cm}^{2}$. Free electron absorption has been considered as a possible mechanism of the reverse-saturable absorption [16]. The dependence of the relaxation times on the copper band structure observed in [37] supports this suggestion. On the other hand, two-photon absorption and free charge carrier absorption for plasmonic nanoparticles are usually observed at exciting light power densities that are higher than those found in the present study.

Another explanation could be the competition between the nonlinear absorption processes in $\mathrm{Cu}$ nanoparticles and those in the diamond-like carbon matrix. Reverse-saturable absorption was found for hydrogenated diamond-like carbon films, similar to the case of some DLC:Cu samples. It should be mentioned that the decrease in transmittance in the case of the DLC film was smaller than that in the case of the DLC:Cu nanocomposites. However, it must be taken into account that the D/G area ratio (the $\mathrm{sp}^{3} / \mathrm{sp}^{2}$ carbon bond ratio) in all DLC:Cu samples studied was substantially larger than the D/G area ratio of the ion beam-deposited DLC film. According to Figure $4 \mathrm{~b}$ and [26], it was 1-2 and $\sim 0.55$ respectively. The $\mathrm{sp}^{3} / \mathrm{sp}^{2}$ bond ratio has a substantial influence on the linear optical properties of diamond-like carbon $[23,26]$. Particularly, the optical bandgap increased threefold as the $\mathrm{sp}^{3} / \mathrm{sp}^{2}$ ratio increased from 0.25 to 4 [23]. Similar behavior with respect to nonlinear optical properties can be supposed in our case.

Considering possible applications of the studied DLC:Cu films, it should be mentioned that both saturable absorption and reverse-saturable absorption was found for these films. Therefore, different DLC:Cu films can be used as both self-saturable absorbers and optical limiters. Their advantage over the SESAM [1,2,4], usually deposited by molecular beam epitaxy (see, e.g., [38]), is room temperature growth and a relatively simple large area deposition compatible technique. DLC films are already used for the protection of different components such as beam splitters [39], infrared windows [40,41], optical windows [23], and bar code scanners [42]. Therefore, the advantage of DLC:Cu films over the other 
nonlinear optical nanomaterials such as plasmonic nanoparticles, graphene, and carbon nanotubes would be the combination of their optical properties with hardness [43,44]. However, further research is necessary to optimize the nonlinear optical properties of DLC:Cu films.

\section{Conclusions}

In conclusion, diamond-like carbon films with embedded copper nanoparticles (DLC:Cu) films deposited by high power pulse magnetron sputtering were studied. An increase in the number of $\mathrm{Cu}$ nanoclusters with increased copper atomic concentration was observed. Afterward, coalescence of the $\mathrm{Cu}$ nanoparticles and the formation of the $\mathrm{Cu}$ network followed. The Raman scattering spectra of DLC:Cu films in all cases were typical of diamond-like carbon. A surface plasmon resonance-related peak was recorded in the absorption spectra for all studied DLC:Cu films. The position of the plasmonic peak maximum was in the 590-620 nm range, even though the $\mathrm{Cu}$ amount in the films experienced a change to three times. Investigation of the nonlinear optical properties of the samples revealed that reverse-saturable absorption is typical for the samples containing lower amounts of copper. For the DLC: $\mathrm{Cu}$ films containing 58-62 atom \% Cu, a saturable absorption effect was observed. However, in some places of the samples, a reverse-saturable absorption was still seen. The presence of both saturable and reverse-saturable absorption effects in the same sample was explained by lateral inhomogeneities of the DLC:Cu films. Some correlation between the photoexcited charge carrier relaxation times and nonlinear optical properties was revealed. In the case of the samples with a lower relaxation time, the reverse-saturable absorption was observed. Longer relaxation times correlated with the presence of the saturable absorption effect. This was explained by the prevailing of the intraband transitions or two-photon absorption, by the free charge carrier absorption at different relaxation times, and/or by the competition between the nonlinear absorption processes in $\mathrm{Cu}$ nanoparticles and in the diamond-like carbon matrix.

Author Contributions: Conceptualization, Š.M.; Methodology, K.V.; Investigation, M.A., A.V., V.K., A.J., D.P. and K.V.; Writing-Original Draft Preparation, Š.M. and M.A.; Writing—Review and Editing, S.T.; Validation, K.V.; Visualization, Š.M., M.A., D.P. and K.V.; Project Administration, Š.M.; Funding Acquisition, Š.M.

Funding: This research was funded by a grant (proposal No. P-MIP-17-243, contract No. S-MIP-17-82) from the Research Council of Lithuania, project title "Plasmonic Carbon Nanocomposite Based Self Saturable Absorber Mirrors for Fiber Lasers."

Acknowledgments: Support from the Research Council of Lithuania is acknowledged.

Conflicts of Interest: The authors declare no conflict of interest.

\section{References}

1. Fibre Lasers Focus issue. Nat. Photonics 2013, 7, 841-932. [CrossRef]

2. Nishizawa, N. Wideband ultrafast fiber laser sources for OCT and metrology. J. Phys. B At. Mol. Opt. Phys. 2016, 49, 182003. [CrossRef]

3. Chan, C.-W.; Carson, L.; Smith, G.C.; Morelli, A.; Lee, S. Enhancing the antibacterial performance of orthopaedic implant materials by fibre laser surface engineering. Appl. Surf. Sci. 2017, 404, 67-81. [CrossRef]

4. Hader, J.; Yang, H.-J.; Scheller, M.; Moloney, J.V.; Koch, S.W. Microscopic analysis of saturable absorbers: Semiconductor saturable absorber mirrors versus graphene. J. Appl. Phys. 2016, 119, 053102. [CrossRef]

5. Ahmad, H.; Ruslan, N.E.; Ismail, M.A.; Ali, Z.A.; Reduan, S.A.; Lee, C.S.J.; Harun, S.W. Silver nanoparticle-film based saturable absorber for passively Q-switched erbium-doped fiber laser (EDFL) in ring cavity configuration. Laser Phys. 2016, 26, 095103. [CrossRef]

6. Kang, Z.; Li, Q.; Gao, X.J.; Zhang, L.; Jia, Z.X.; Feng, Y.; Qin, G.S.; Qin, W.P. Gold nanorod saturable absorber for passive mode-locking at $1 \mu \mathrm{m}$ wavelength. Laser Phys. Lett. 2014, 11, 035102. [CrossRef]

7. Elim, H.I.; Yang, J.; Lee, J.-Y.; Mi, J.; Ji, W. Observation of saturable and reverse-saturable absorption at longitudinal surface plasmon resonance in gold nanorods. Appl. Phys. Lett. 2006, 88, 083107. [CrossRef]

8. Kang, Z.; Guo, X.; Jia, Z.; Xu, Y.; Liu, L.; Zhao, D.; Qin, G.; Qin, W. Gold nanorods as saturable absorbers for all fiber passively Q-switched erbium-doped fiber laser. Opt. Mater. Express 2013, 3, 1986-1991. [CrossRef] 
9. Zheng, C.; Du, Y.; Feng, M.; Zhan, H. Shape dependence of nonlinear optical behaviors of nanostructured silver and their silica gel glass composites. Appl. Phys. Lett. 2008, 93, 143108. [CrossRef]

10. Jiang, T.; Xu, Y.; Tian, Q.; Liu, L.; Kang, Z.; Yang, R.; Qin, G.; Qin, W. Passively Q-switching induced by gold nanocrystals. Appl. Phys. Lett. 2012, 101, 151122. [CrossRef]

11. Nigoghossian, K.; dos Santos, M.V.; Barud, H.S.; da Silva, R.R.; Rocha, L.A.; Caiut, J.M.A.; de Assunção, R.M.N.; Spanhel, L.; Poulain, M.; Messaddeq, Y.; et al. Orange pectin mediated growth and stability of aqueous gold and silver nanocolloids. Appl. Surf. Sci. 2015, 341, 28-36. [CrossRef]

12. Tamulevičius, S.; Meškinis, Š.; Tamulevičius, T.; Rubahn, H.-G. Diamond like carbon nanocomposites with embedded metallic nanoparticles. Rep. Prog. Phys. 2018, 81, 024501. [CrossRef] [PubMed]

13. Ghosh, B.; Chakraborty, P.; Singh, B.P.; Kundu, T. Enhanced nonlinear optical responses in metal-glass nanocomposites. Appl. Surf. Sci. 2009, 256, 389-394. [CrossRef]

14. Wu, D. Saturable Absorption of Copper Nanowires in Visible Regions for Short-Pulse Generation. IEEE Photonics J. 2016, 8, 4501507. [CrossRef]

15. Muhammad, A.R.; Ahmad, M.T.; Zakaria, R.; Rahim, H.R.A.; Yusoff, S.F.A.Z.; Hamdan, K.S.; Yusof, H.H.M.; Arof, H.; Harun, S.W. Q-Switching Pulse Operation in 1.5- $\mu \mathrm{m}$ Region Using Copper Nanoparticles as Saturable Absorber. Chin. Phys. Lett. 2017, 34, 034205. [CrossRef]

16. Philip, R.; Chantharasupawong, P.; Qian, H.; Jin, R.; Thomas, J. Evolution of Nonlinear Optical Properties: From Gold Atomic Clusters to Plasmonic Nanocrystals. Nano Lett. 2012, 12, 4661-4667. [CrossRef] [PubMed]

17. Yadav, R.K.; Aneesh, J.; Sharma, R.; Abhiramnath, P.; Maji, T.K.; Ji Omar, G.; Mishra, A.K.; Karmakar, D.; Adarsh, K.V. Designing Hybrids of Graphene Oxide and Gold Nanoparticles for Nonlinear Optical Response. Phys. Rev. Appl. 2018, 9, 044043. [CrossRef]

18. Gurudas, U.; Brooks, E.; Bubb, D.M.; Heiroth, S.; Lippert, T.; Wokaun, A. Saturable and reverse saturable absorption in silver nanodots at $532 \mathrm{~nm}$ using picosecond laser pulses. J. Appl. Phys. 2008, 104, 073107. [CrossRef]

19. Ganeev, R.A.; Ryasnyansky, A.I.; Stepanov, A.L.; Usmanov, T. Characterization of nonlinear optical parameters of copper- and silver-doped silica glasses at $\lambda=1064 \mathrm{~nm}$. Phys. Stat. Sol. 2004, 241, 935-944. [CrossRef]

20. Dhanya, N.P. Non linear optical investigations of silver nanoparticles synthesised by curcumin reduction. Opt. Mater. 2017, 73, 384-387. [CrossRef]

21. Dadhich, B.K.; Kumar, I.; Choubey, R.K.; Bhushan, B.; Priyam, A. Shape and size dependent nonlinear refraction and absorption in citrate-stabilized, near-IR plasmonic silver nanopyramids. Photochem. Photobiol. Sci. 2017, 16, 1556-1562. [CrossRef] [PubMed]

22. Zasedatelev, A.; Dubinina, T.; Krasovskii, V.; Suprunova, O.; Tomilova, L.; Chistyakov, A. Resonant plasmon-stimulated nonlinear absorption in three-level systems. J. Phys. Conf. Ser. 2015, 643, 012049. [CrossRef]

23. Robertson, J. Diamond-like amorphous carbon. Mater. Sci. Eng. R 2002, 37, 129-281. [CrossRef]

24. Chen, S.-Y.; Ou, K.-L.; Huang, W.-C.; Chu, K.-T.; Ou, S.-F. Phase transformation of diamond-like carbon/silver composite films by sputtering deposition. Ceram. Int. 2013, 39, 2575-2580. [CrossRef]

25. Cheng, C.-H.; Lin, Y.; Chen, T.; Chen, H.; Chi, Y.; Lee, C.; Wu, C.; Lin, G. Can silicon carbide serve as a saturable absorber for passive mode-locked fiber lasers? Sci. Rep. 2016, 5, 16463. [CrossRef] [PubMed]

26. Meškinis, Š.; Kopustinskas, V.; Tamulevičienè, A.; Tamulevičius, S.; Niaura, G.; Jankauskas, J.; Gudaitis, R. Ion beam energy effects on structure and properties of diamond like carbon films deposited by closed drift ion source. Vacuum 2010, 84, 1133-1137. [CrossRef]

27. Ferrari, A.C.; Robertson, J. Raman spectroscopy of amorphous, nanostructured, diamond-like carbon, and nanodiamond. Philos. Trans. R. Soc. Lond. A 2004, 362, 2477-2512. [CrossRef]

28. Cui, W.G.; Lai, Q.B.; Zhang, L.; Wang, F.M. Quantitative measurements of $\mathrm{sp}^{3}$ content in DLC films with Raman spectroscopy. Surf. Coat. Technol. 2010, 205, 1995-1999. [CrossRef]

29. Viskontas, K.; Rusteika, N. All-fiber wavelength-tunable picosecond nonlinear reflectivity measurement setup for characterization of semiconductor saturable absorber mirrors. Opt. Fiber Technol. 2016, 31, 74-82. [CrossRef]

30. Meškinis, Š.; Čiegis, A.; Vasiliauskas, A.; Šlapikas, K.; Tamulevičius, T.; Andrulevičius, M.; Niaura, G.; Tamulevičius, S. Effects of the High Power Pulsed Magnetron Sputtering Deposition Conditions on Structure of Diamond Like Carbon:Cu Films. J. Nanosci. Nanotechnol. 2016, 16, 10133-10142. [CrossRef] 
31. Gerhards, I.; Ronning, C.; Vetter, U.; Hofsass, H.; Gibhardt, H.; Eckold, G.; Li, Q.; Lee, S.T.; Huang, Y.L.; Seibt, M. Ion beam synthesis of amorphous carbon thin films containing metallic nanoclusters. Surf. Coat. Technol. 2002, 158, 114-119. [CrossRef]

32. Chan, Y.H.; Huang, C.F.; Ou, K.L.; Peng, P.W. Mechanical properties and antibacterial activity of copper doped diamond-like carbon films. Surf. Coat. Technol. 2011, 206, 1037-1040. [CrossRef]

33. Peckus, D.; Tamulevičius, T.; Meškinis, Š.; Tamulevičienè, A.; Vasiliauskas, A.; Ulčinas, O.; Gulbinas, V.; Tamulevičius, S. Linear and Nonlinear Absorption Properties of Diamond-Like Carbon Doped With $\mathrm{Cu}$ Nanoparticles. Plasmonics 2017, 12, 47-58. [CrossRef]

34. Hua, Y.; Chandra, K.; Dam, D.H.M.; Wiederrecht, G.P.; Odom, T.W. Shape-Dependent Nonlinear Optical Properties of Anisotropic Gold Nanoparticles. J. Phys. Chem. Lett. 2015, 6, 4904-4908. [CrossRef]

35. Wang, H.; Tam, F.; Grady, N.K.; Halas, N.J. Cu Nanoshells: Effects of Interband Transitions on the Nanoparticle Plasmon Resonance. J. Phys. Chem. B 2005, 109, 18218-18222. [CrossRef] [PubMed]

36. Kiran, P.P.; Bhaktha, B.N.S.; Rao, D.N.; De, G. Nonlinear optical properties and surface-plasmon enhanced optical limiting in Ag-Cu nanoclusters co-doped in $\mathrm{SiO}_{2}$ Sol-Gel films. J. Appl. Phys. 2004, 96, 6717. [CrossRef]

37. Knoesel, E.; Hotzel, A.; Wolf, M. Ultrafast dynamics of hot electrons and holes in copper: Excitation, energy relaxation, and transport effects. Phys. Rev. B 1998, 57, 12812-12823. [CrossRef]

38. Schättiger, F.; Bauer, D.; Demsar, J.; Dekorsy, T.; Kleinbauer, J.; Sutter, D.H.; Puustinen, J.; Guina, M. Characterization of InGaAs and InGaAsN semiconductor saturable absorber mirrors for high-power mode-locked thin-disk lasers. Appl. Phys. B 2012, 106, 605-612. [CrossRef]

39. Baranov, A.; Mikhailov, A.V. Hybrid beam splitter coatings with a diamond-like layer on zinc selenide. J. Opt. Technol. 2018, 85, 656-659. [CrossRef]

40. Ankit, K.; Varade, A.; Reddy, K.N.; Chellamalai, S.M.; Balashanmugam, N.; Krishna, P. Synthesis of high hardness IR optical coating using diamond-like carbon by PECVD at room temperature. Diam. Relat. Mater. 2017, 78, 39-43.

41. Pan, Y.Q.; Hang, L.X.; Wu, Z.S.; Yin, Y.B. Design and fabrication of ultra broadband infrared antireflection hard coatings on ZnSe in the range from 2 to $16 \mu \mathrm{m}$. Infrared Phys. Technol. 2009, 52, 193-195. [CrossRef]

42. Robertson, J. Comparison of diamond-like carbon to diamond for applications. Phys. Stat. Sol. 2008, 205, 2233-2244. [CrossRef]

43. Chen, C.-C.; Hong, F.C.-N. Structure and properties of diamond-like carbon nanocomposite films containing copper nanoparticles. Appl. Surf. Sci. 2005, 242, 261-269. [CrossRef]

44. Zhang, H.; Chen, Y.; Liao, B.; Wu, X.; Zhang, H.; Zhang, X. Effect of $\mathrm{C}_{2} \mathrm{H}_{2}$ flow rate on microstructure and properties of nc-Cu/a-C:H nanocomposite films prepared by filtered cathodic vaccum arc technique. Nucl. Instrum. Methods Phys. Res. B 2013, 307, 137-142. [CrossRef] 